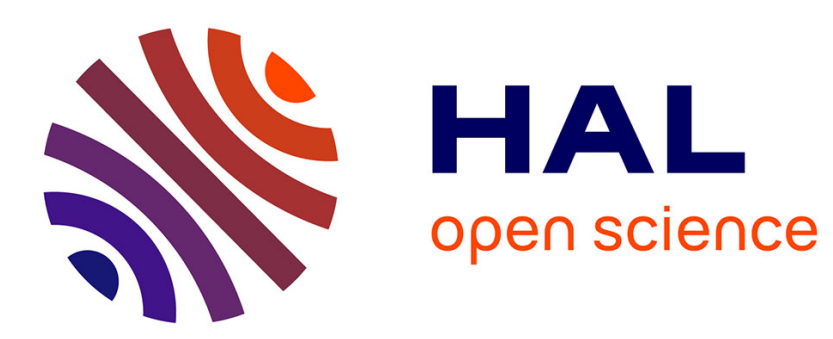

\title{
Plasticity criterion for hot forming of Aluminum-Lithium alloy
}

Wael Younes, Eliane Giraud, Philippe Dal Santo

\section{To cite this version:}

Wael Younes, Eliane Giraud, Philippe Dal Santo. Plasticity criterion for hot forming of Aluminum-Lithium alloy. ESAFORM2015, Apr 2015, Graz, Austria. pp.1103-1108, 10.4028/www.scientific.net/KEM.651-653.1103 . hal-01186361

\section{HAL Id: hal-01186361 https://hal.science/hal-01186361}

Submitted on 24 Aug 2015

HAL is a multi-disciplinary open access archive for the deposit and dissemination of scientific research documents, whether they are published or not. The documents may come from teaching and research institutions in France or abroad, or from public or private research centers.
L'archive ouverte pluridisciplinaire HAL, est destinée au dépôt et à la diffusion de documents scientifiques de niveau recherche, publiés ou non, émanant des établissements d'enseignement et de recherche français ou étrangers, des laboratoires publics ou privés. 


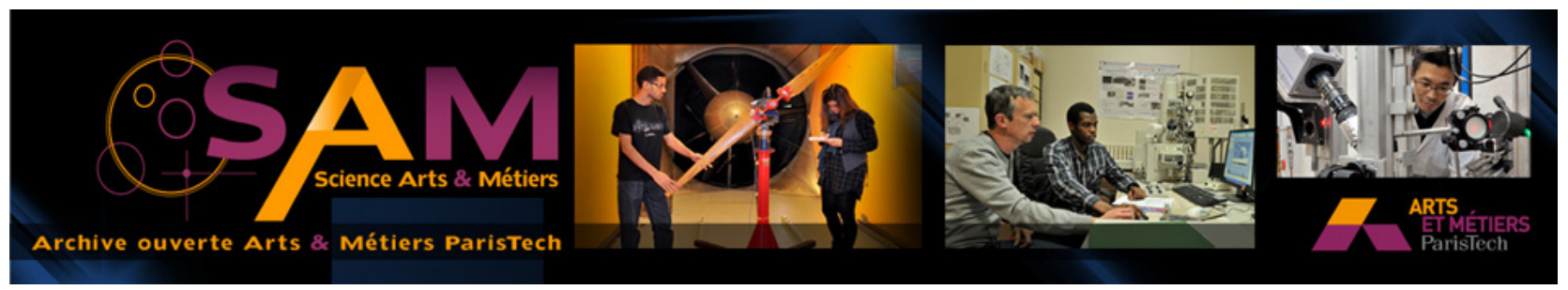

Science Arts \& Métiers (SAM)

is an open access repository that collects the work of Arts et Métiers ParisTech researchers and makes it freely available over the web where possible.

This is an author-deposited version published in: http://sam.ensam.eu

Handle ID: .http://hdl.handle.net/10985/9856

\section{To cite this version :}

Wael YOUNES, Eliane GIRAUD, Philippe DAL SANTO - Plasticity criterion for hot forming of Aluminum-Lithium alloy - In: ESAFORM2015, Autriche, 2015-04-14 - Key Engineering Materials 2015 


\title{
Plasticity criterion for hot forming of Aluminum-Lithium alloy
}

\author{
W. Younes ${ }^{1,2, a^{*}}$, E. Giraud ${ }^{2, b}$, P. Dal Santo ${ }^{2, c}$ \\ ${ }^{1}$ IRT Jules Verne, Chemin du Chaffault, 44340 Bouguenais - France \\ ${ }^{2}$ LAMPA, ENSAM, 2 boulevard du Ronceray, 49035 Angers, Cedex 01 - France \\ aWael.Younes@irt-jules-verne.fr, ${ }^{\text {b} E l i a n e . G i r a u d @ e n s a m . e u, ~}{ }^{c}$ Philippe.DalSanto@ensam.eu
}

Keywords: Plasticity criterion, Hot forming, Aluminum-Lithium

\begin{abstract}
Anisotropic behavior at high temperature of an Aluminum-Lithium alloy was studied. Mechanical tests at a temperature of $350^{\circ} \mathrm{C}$ and a strain rate of $10^{-2} \mathrm{~s}^{-1}$ were carried out on samples taken at different angles with respect to the rolling direction of the sheet. Two plasticity criteria (HILL48 and HU2005) were identified and implemented in ABAQUS to predict the anisotropic behavior of the alloy for other angles. Results show that: (i) the alloy exhibits an anisotropic behavior at high temperature and some recrystallization occurs during plastic deformation; (ii) the coefficients of anisotropy depend on strain level and (iii) HU2005 criterion allows describing the behavior of the alloy at high temperature.
\end{abstract}

\section{INTRODUCTION}

Aluminum-Lithium alloys are of some interests for aircraft parts such as fuselage panels because of their high resistance and low density [1]. However, their formability by hot forming is not well known. Numerical simulations are generally used to guarantee the final shape of the part. But, the quality of the prediction is directly linked to the material model used which has to be as representative as possible of the mechanical response of the alloy. Consequently, it must include several parts such as a plasticity criterion, an isotropic and kinematic hardening, a viscoplastic law as well as a damage criterion.

The present work is mainly centered on the choice of a plasticity criterion allowing describing the anisotropic behavior at high temperature of this type of alloy. Two criteria are considered: HILL48 [2] and HU2005 [3]. They can be used for 3D cases i.e. for either thin or thick metallic sheets and their parameters are quite easy to identify, which represents two main advantages. The choice of the most appropriate criterion is realized by comparing numerical results to experimental results for tensile experiments (in terms of yield strength and anisotropy coefficient).

\section{EXPERIMENTAL PROCEDURE}

The aluminum-lithium used was supplied by Constellium as rolled plates, $2 \mathrm{~mm}$ in thickness and in the T3 metallurgical condition (solution treatment, hardening and maturation). Tensile specimens were taken from the plates with their tensile direction at various angles from the rolling direction: $0^{\circ}$ (tensile direction parallel to rolling direction), $30^{\circ}, 45^{\circ}, 75^{\circ}$ and $90^{\circ}$. Specimens taken at $0^{\circ}, 45^{\circ}$ and $90^{\circ}$ were used to identify the material model while other specimens were used to check the model. 


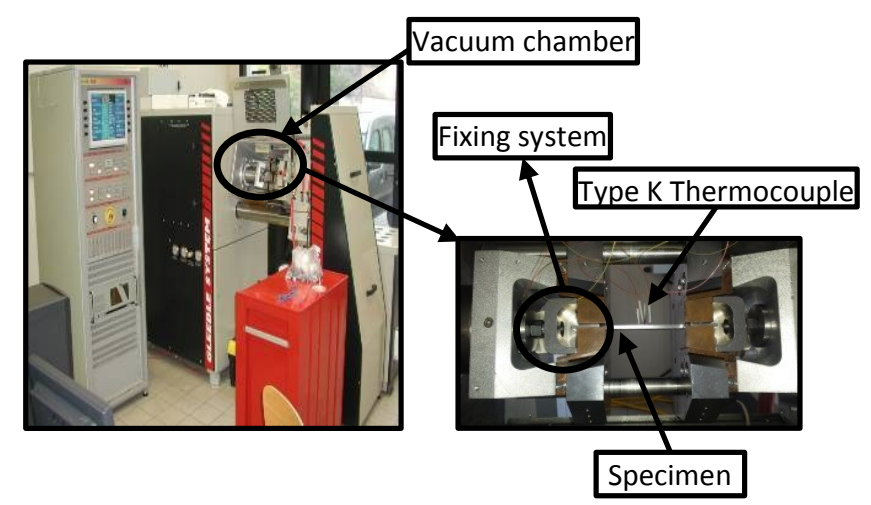

Fig.1. Gleeble 3500 machine

A Gleeble 3500 (Fig. 1) was employed to perform tensile experiments. The specimen was heated by Joule effect at $10 \mathrm{~K} / \mathrm{s}$ until the desired temperature (i.e. $350^{\circ} \mathrm{C}$ ). The temperature was measured by a K-type thermocouple welded in the central part of the sample. The experiment was started after a holding time of $20 \mathrm{~s}$ at the test temperature to ensure a homogeneous temperature. A constant strain rate (of $10^{-2} \mathrm{~s}^{-1}$ ) was applied and monitored in real time by measuring the deformation of the gauge length with a longitudinal extensometer. A transverse extensometer was also used to measure transverse deformation of the gauge length.

\section{EXPERIMENTAL RESULTS}

\subsection{Hot tensile behavior of the aluminum-lithium alloy}

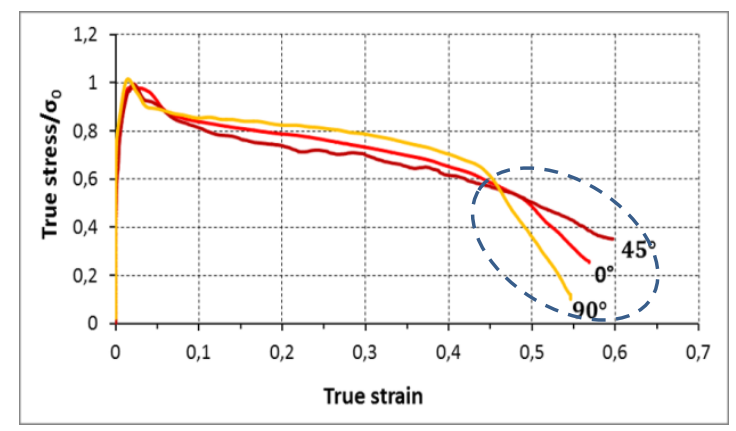

(a)

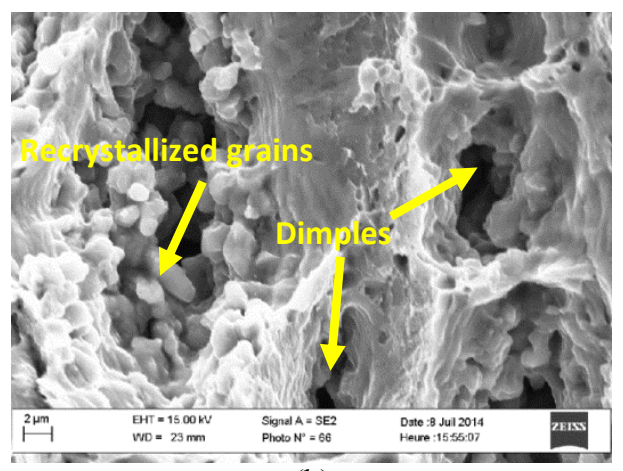

(b)

Fig.2. (a) Normalized stress-strain curves obtained at $350^{\circ} \mathrm{C}$ with a strain-rate of $0.01 \mathrm{~s}^{-1}$ and for three orientations $\left(0^{\circ}, 4^{\circ}\right.$ and $\left.90^{\circ}\right)$ and (b) Fracture morphology

Normalized stress - strain curves obtained at $350^{\circ} \mathrm{C}$ with a strain rate of $10^{-2} \mathrm{~s}^{-1}$ are shown in Fig. 2a: stress has been normalized using the experimental yield strength in the rolling direction i.e. $\sigma_{0}$. Whatever the orientation considered, stress increases until a peak and then decreases following two different slopes. The peak stress can be explained by the recrystallization phenomenon which can be noticed in Fig. 2b: the fracture surface shows indeed recrystallized grains. The slow drop in stress for intermediate strains can be explained by softening mechanisms and some damage evolution: initial voids are indeed present in the material and grow during the deformation. The fast decrease in stress at high strains can be due to the localized necking stage which leads to the failure of the specimen. A ductile transgranular fracture occurs: as shown in Fig. 2b, the fracture surface exhibits some dimples which underline the void coalescence. Specimen orientation has slight effects on stress value except for high strain values (dotted area in Fig. 2a) where strong necking occurs and can maybe disturb the measurement. 


\subsection{Characterization of the anisotropy of the alloy}

The anisotropy of an alloy can be evaluated by determining the coefficients of anisotropy and the yield stresses for each studied orientation. These coefficients for $0^{\circ}, 45^{\circ}$ and $90^{\circ}$ have be determined by using the values given by the longitudinal and transverse extensometers. Yield strength for each orientation has been taken equal to the stress for a strain of $0.2 \%$. Fig. 3 shows the normalized values obtained for the anisotropy coefficient (Fig. 3a) and for the yield strength (Fig. $3 \mathrm{~b}$ ) as a function of grain orientation. R-value and yield strength have been normalized using the values obtained in the rolling direction i.e. $\mathrm{r}_{0}$ and $\sigma_{0}$, respectively. Yield strength is not very sensitive to the specimen orientation whereas r-values differ depending on the specimen orientation: $r_{45}$ is twice as high as $r_{0}$ and $r_{90}$. All $r$-values are superior to 1 , which underlines the anisotropic behavior of the alloy. This evolution of r-values and yield strength with the orientation is frequently observed on aluminum alloys [4,5].

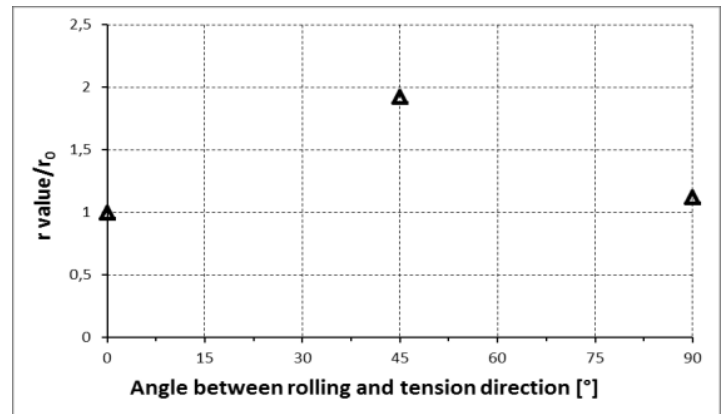

(a)

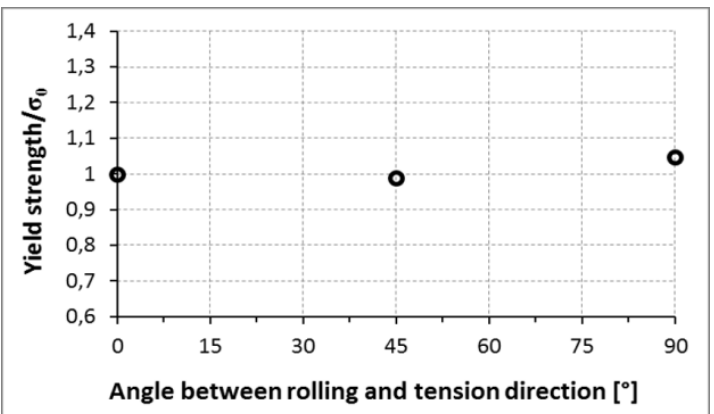

(b)

Fig.3. Normalized r-values and normalized Yield strength as a function of grain orientation $\left(350^{\circ} \mathrm{C}\right.$ and $\left.0.01 \mathrm{~s}^{-1}\right)$

The normalized anisotropy coefficients given in Fig. 3a correspond to mean values within a strain range from the beginning of the plastic domain to the beginning of the necking of the sample. In fact, as shown in Fig. 4, the anisotropy of the alloy depends on strain level. When increasing plastic strain and exceeding a strain of $20 \%$, the anisotropy of the alloy increases: the normalized $r-$ value can be doubled. This evolution in normalized r-values can maybe be explained by a change in aspect ratio of grain for high strains [6]. In the rest of the study, only mean values are considered.

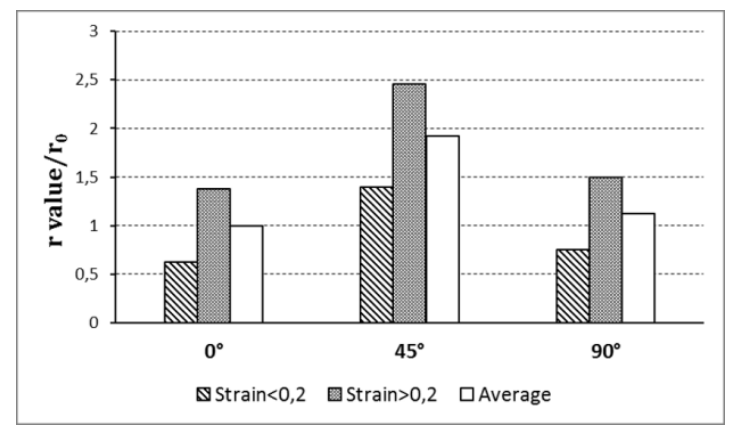

Fig.4. Evolution of normalized r-values with strain level at a temperature of $350^{\circ} \mathrm{C}$ and with a strain-rate of $0.01 \mathrm{~s}^{-1}$ 


\section{PLASTICITY CRITERIA}

\subsection{Plasticity criterion of Hill48 [2]}

The load function $\mathrm{f}$ for Hill48 is defined as follow:

$$
=\sqrt{H\left(\sigma_{11}-\sigma_{22}\right)^{2}+F\left(\sigma_{22}-\sigma_{33}\right)^{2}+G\left(\sigma_{33}-\sigma_{11}\right)^{2}+2 N\left(\sigma_{12}\right)^{2}+2 M\left(\sigma_{23}\right)^{2}+2 L\left(\sigma_{13}\right)^{2}}-R_{0}
$$

Where: $\mathrm{R}_{0}$ is the yield strength in the rolling direction $\left(\alpha=0^{\circ}\right), \mathrm{H}, \mathrm{F}, \mathrm{G}, \mathrm{N}, \mathrm{M}$ and $\mathrm{L}$ are material parameters, $\sigma_{i j}$ are the stress components. There are two methods to determine material parameters (Table 1). The first one consists in using the anisotropy coefficients $\left(r_{0}, r_{45}\right.$ and $\left.r_{90}\right)$. The second one consists in using the yield strengths $\left(\sigma_{0}, \sigma_{45}, \sigma_{90}\right)$ and the anisotropy coefficient $\left(\mathrm{r}_{45}\right)$.

Table 1. Equations of material parameters for Hill48 as a function of identification method

\begin{tabular}{|c|cc|}
\hline Method 1 & $G+H=\left(\frac{R_{0}}{\sigma_{0}}\right)^{2}=1 \quad G=\frac{1}{r_{0}+1} \quad F=\frac{H}{r_{90}} \quad N=\frac{(F+G)\left(2 r_{45}+1\right)}{2}$ \\
\hline Method 2 & $H=-\frac{1}{2}\left[\left(\left(\frac{R_{0}}{\sigma_{45}}\right)^{2} \times \frac{2}{r_{45}+1}\right)-\left(\frac{R_{0}}{\sigma_{90}}\right)^{2}-1\right] \quad G+H=\left(\frac{R_{0}}{\sigma_{0}}\right)^{2}=1 \quad F+H=\left(\frac{R_{0}}{\sigma_{90}}\right)^{2}$ \\
$N=\frac{(F+G)\left(2 r_{45}+1\right)}{2}$
\end{tabular}

\subsection{Plasticity criterion of HU2005 [3]}

The load function F for HU2005 is defined as follow:

$$
\begin{gathered}
\mathrm{F}=\mathrm{X}_{1}\left(\sigma_{11}-\sigma_{33}\right)^{4}+\mathrm{X}_{2}\left(\sigma_{11}-\sigma_{33}\right)^{3}\left(\sigma_{22}-\sigma_{33}\right)+\mathrm{X}_{3}\left(\sigma_{11}-\sigma_{33}\right)^{2}\left(\sigma_{22}-\sigma_{33}\right)^{2}+ \\
\mathrm{X}_{4}\left(\sigma_{11}-\sigma_{33}\right)\left(\sigma_{22}-\sigma_{33}\right)^{3}+\mathrm{X}_{5}\left(\sigma_{22}-\sigma_{33}\right)^{4}+\mathrm{X}_{6}\left(\sigma_{12}{ }^{2}+\sigma_{23}{ }^{2}+\sigma_{31}{ }^{2}\right) \times\left[\left(\sigma_{11}-\sigma_{33}\right)^{2}+\right. \\
\left.\left(\sigma_{22}-\sigma_{33}\right)^{2}-\left(\sigma_{11}-\sigma_{33}\right)\left(\sigma_{22}-\sigma_{33}\right)\right]+\mathrm{X}_{7}\left(\sigma_{12}{ }^{2}+\sigma_{23}{ }^{2}+\sigma_{31}{ }^{2}\right)^{2}-1=0
\end{gathered}
$$

Where $\mathrm{X}_{\mathrm{i}}$ is material parameters and $\sigma_{\mathrm{ij}}$ are the stress components. The material parameters depend on yield strength and anisotropy coefficients, as illustrated in Table 2. An equibiaxialtension yield stress $\left(\sigma_{b}\right)$ is introduced in parameters $X_{3}$ and $X_{6}$. This stress is calculated by using the relation proposed by $\mathrm{Hu}[3]$.

Table 2. Equations of material parameters for HU2005

\begin{tabular}{|c|c|c|c|}
\hline $\mathbf{X}_{\mathbf{i}}$ & Equations & $\mathbf{X}_{\mathbf{i}}$ & Equations \\
\hline $\mathrm{X}_{1}$ & $\frac{1}{\sigma_{0}^{4}}$ & $\mathrm{X}_{5}$ & $\frac{1}{\sigma_{90}^{4}}$ \\
\hline $\mathrm{X}_{2}$ & $-\frac{4 \mathrm{R}_{0}}{\left(1+\mathrm{R}_{0}\right) \sigma_{0}^{4}}$ & $\mathrm{X}_{6}$ & $\frac{16}{\left(1+\mathrm{R}_{45}\right) \sigma_{45}^{4}}-\frac{2}{\sigma_{\mathrm{b}}^{4}}$ \\
\hline $\mathrm{X}_{4}$ & $-\frac{4 \mathrm{R}_{90}}{\left(1+\mathrm{R}_{90}\right) \sigma_{90}^{4}}$ & $\mathrm{X}_{7}$ & $\frac{1}{\sigma_{0}^{4}}+\frac{16 \mathrm{R}_{45}}{\left(1+\mathrm{R}_{45}\right) \sigma_{45}^{4}}$ \\
\hline $\mathrm{X}_{3}$ & $\frac{1}{\sigma_{\mathrm{b}}^{4}}-\frac{1}{\sigma_{0}^{4}}-\frac{1}{\sigma_{90}^{4}}+\frac{4 \mathrm{R}_{0}}{\left(1+\mathrm{R}_{0}\right) \sigma_{0}^{4}}+\frac{4 \mathrm{R}_{90}}{\left(1+\mathrm{R}_{90}\right) \sigma_{90}^{4}}$ \\
\hline
\end{tabular}




\section{NUMERICAL SIMULATION}

A 3D model of tensile experiments has been realized in ABAQUS. It consists in a quarter of the tensile specimen and three boundary conditions of symmetry along the three axes are applied. The deformation of the specimen until a strain of $30 \%$ is performed by an imposed displacement along the $\mathrm{X}$-axis in order to have a strain rate of $0.01 \mathrm{~s}^{-1}$. A C3D8H element type with full integration is used. The size of each element is about $0.5 \times 0.5 \times 0.5 \mathrm{~mm}$. Each plasticity criterion (Hill 48 and $\mathrm{Hu} 2005$ ) has been implemented in ABAQUS by using a user material subroutine (UMAT). The mechanical response of the material during plastic flow has been taken into account by using, in the UMAT, an UHARD subroutine which gives the evolution of stress as a polynomial function of true strain.

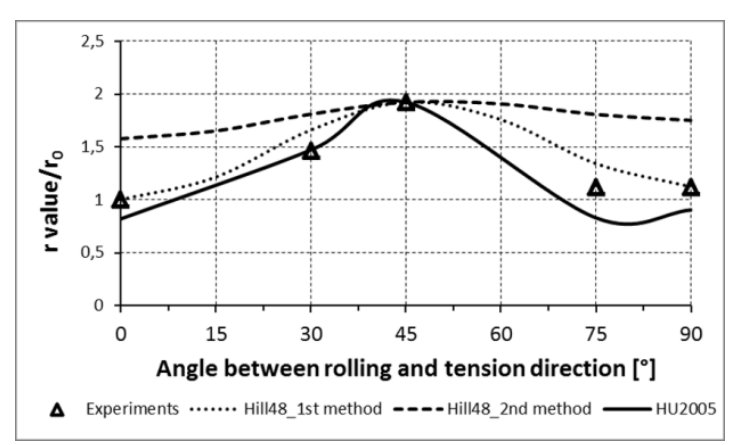

(a)

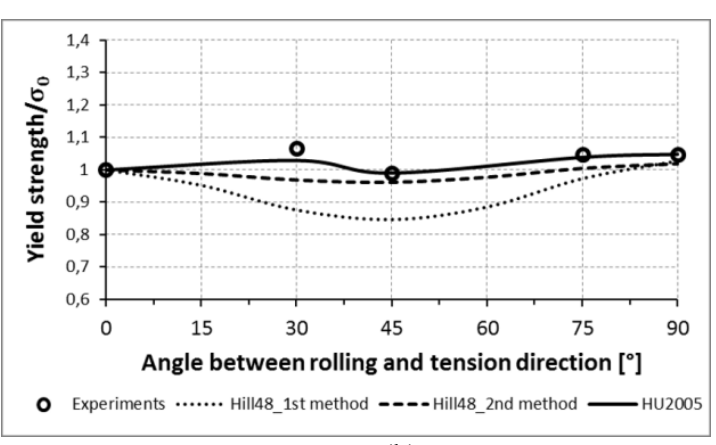

(b)

Fig.5. Comparison of numerical and experimental results of r-values and Yield strength for: $0^{\circ}, 30^{\circ}, 45^{\circ}, 75^{\circ}$ and $90^{\circ}$

Experimental normalized r-values and yield strengths are compared to numerical results in Fig. 5: new orientations $\left(30^{\circ}\right.$ and $\left.75^{\circ}\right)$ are studied in order to check the prediction quality of the anisotropic behavior of the material whatever the orientation used. For Hill48 criterion, numerical rvalues are in good agreement with experimental ones when using the parameters identified with the first method (Fig. 5a) whereas some differences are present between numerical yield strengths and experimental ones (Fig. 5b). An inverted response is observed when using the parameters identified with the second method. For Hu2005 criterion, a good agreement is found between numerical and experimental results in terms of r-values (Fig. 5a) and yield strengths (Fig. 5b).

\section{CONCLUSION}

The mechanical behavior at high temperature of an aluminum-lithium alloy has been investigated. The alloy exhibits an anisotropic behavior which depends on strain level. Plasticity criteria, Hill48 and Hu2005, have been identified and implemented in Abaqus to predict the anisotropic response of the alloy by using a user material subroutine (UMAT). A good approval is found for uni-axial stress states with the plasticity criterion of $\mathrm{Hu} 2005$.

Next steps in these works will consist in: (i) studying the quality of the prediction of the anisotropic response for biaxial stress state by using HU2005 criterion and (ii) implementing a more complex material model including viscoplastic law, isotropic and kinematic hardening and damage criterion. This model will allow predicting the hot forming of thin and thick sheets as well as the springback.

\section{ACKNOWLEDGEMENTS}

This paper is part of the METAFOR project managed by IRT Jules Verne (French Institute in Research and Technology in Advanced Manufacturing Technologies for Composite, Metallic and 
Hybrid Structures). The authors wish to associate the industrial and academic partners of this project; respectively ACB, STELIA, AIRBUS, CONSTELLIUM, ENSAM. The authors thank Mr. Alain POTIRON, ENSAM, for his help in the development of the UMAT.

\section{REFERENCES}

[1] P. Vincent, Characterization and comprehension of corrosion behavior of structures in aluminum-lithium-copper 2050 assembled by Friction Stir Welding (FSW), Thesis, University of Toulouse, 2012.

[2] R. Hill, A theory of the yielding and plastic flow of anisotropic metals, Proc. Royal Soc. London. Series A, Math. Phys. Sci. 193(1033), (1948) 281-297.

[3] W. Hu, An orthotropic yield criterion in a 3-D general stress state, International Journal of Plasticity, Vol 21, (2005) 1771-1796.

[4] S.-H. Choi, J.C. Brem, F. Barlat, K.H. Oh, Macroscopic anisotropy in AA5019A sheets, Acta Materialia, Vol 48, (2000) 1853-1863.

[5] S.-H. Choi, F. Barlat, Prediction of macroscopic anisotropy in rolled Aluminum-Lithium sheet, Scripta Materialia, Vol 41, (1999) 981-987.

[6] C. Snippe, Design and optimization of vertex detector foils by superplastic forming, Thesis, University of Twente, 2011. 